\title{
Peramalan Harga Garam Konsumsi Menggunakan Artificial Neural Network Feedforward-Backpropagation (Studi Kasus : PT. Garam Mas, Rembang, Jawa Tengah)
}

\author{
Mochammad Yusuf Habibi dan Edwin Riksakomara \\ Departemen Sistem Informasi, Fakultas Teknologi dan Informasi, Institut Teknologi Sepuluh \\ Nopember (ITS) \\ e-mail: erk@is.its.ac.id
}

\begin{abstract}
Abstrak-Garam merupakan salah satu komoditas strategis, karena selain merupakan kebutuhan pokok manusia, garam juga digunakan sebagai bahan baku industri. Indonesia menjadi salah satu negara yang memproduksi garam. Akan tetapi Indonesia belum bisa memenuhi kebutuhan garam dalam negeri. Kabupaten Rembang sebagai salah satu daerah penghasil garam, baik garam konsumsi maupun garam industri. Salah satu perusahaan yang mengolah garam adalah PT. Garam Mas. Pada perusahaan tersebut sudah melayani permintaan pasar di wilayah Jawa Tengah-DIY dan sebagian wilayah Sumatra. Masih banyak industri di Indonesia yang memilih garam impor dibandingkan dengan garam lokal. Hal tersebut sangat merugikan, baik bagi petani maupun bagi pemilik usaha pengolahan garam. Karena membuat harga garam lokal menjadi tidak menentu. Untuk itu perlu dibuat strategi bisnis yang tepat agar dapat meminimalisir kerugian tersebut. Untuk mendukung strategi tersebut perlu dilakukan sebuah permalan harga garam. Dimana hasil peramalan dapat dijadikan acuan untuk mengatur strategi bisnis yang tepat. Pada penelitian ini, digunakan metode Artificial Neural Network. Model yang dihasilkan pada penelitian ini memiliki nilai MAPE sebesar $4.394 \%$. Hal tersebut menunjukkan bahwa model yang dihasilkan memiliki hasil permalan yang sangat baik. Kemudian pada penelitian studi ini juga dibuat sebuah visualisasi agar perusahaan dapat dengan mudah menggunakan model yang dihasilkan pada penelitian studi ini untuk meramalkan harga garam di periode selanjutnya. Penelitian studi ini diharapkan dapat menjadi salah satu elemen pendukung keputusan terkait tentang penjualan oleh perusahaan.
\end{abstract}

Kata Kunci-Peramalan, Garam, Artificial Neural Network.

\section{PENDAHULUAN}

$\mathrm{G}$ ARAM merupakan salah satu komoditas strategis, karena selain merupakan kebutuhan pokok manusia, garam juga digunakan sebagai bahan baku industri. Untuk memenuhi kebutuhan pokok manusia, garam yang digunkana adalah garam konsumsi, sedangkan untuk memnuhi kebutuhan industri adalah garam industri. Yang membedakan garam konsumsi dan garam industri adalah kandungan NaCL (Natrium Klorida) pada garam. Garam konsumsi mempunyai kandungan NaCL sebesar 94\%, sedangkan garam industri memiliki kandungan NaCL sebesar 97\%. Dengan kata lain kandungan air dari garam industri lebih sedikit dibandingkan dengan garam konsumsi. [1]

Terbentuknya garam dibagi menjadi dua yaitu terbentuk secara alami dan sengaja dibentuk oleh manusia. Maksud dari garam terbentuk secara alami adalah garam terbentuk pada batu atau dari halte dari deposit. Kemudian batu tersebut ditambang selayaknya bahan tambang bebatuan untuk mengambil kandungan garamnya. Tambang garam biasanya terdapat pada daerah dimana pernah terdapat air yang kemudian mengering. Sedangkan garam yang sengaja dibentuk oleh manusia biasanya menggunakan sistem penguapan air laut menggunakan sinar matahari diatas lahan tanah ataupun dengan cara memasak air laut untuk diambil kandungan garamnya. [2]

Pembuatan garam di Indonesia sebagian besar dengan cara sengaja dibentuk oleh manusia. Daerah yang memiliki tanah yang mendukung, menggunakan cara sistem penguapan air laut menggunakan sinar matahari diatas lahan tanah, sedangkan daerah yang tidak memiliki tanah yang mendukung, menggunakan cara memasak air kaut untuk diambil kandungan garamnya. Produktifitas pada setiap daerah tidaklah sama, hal ini disebabkan beberapa faktor yaitu kualitas tanah, kelembaban udara, kecepatan angin, sistem yang digunakan, dan masih banyak faktor lain yang mempengaruhi. Perkiraan produksi garam pada setiap tahun masih sulit diprediksi karena sangat tergantung pada iklim yang ada, sedangkan iklim saat ini cenderung berubah-ubah tidak menentu. Jadi industri pengolahan garam tidak seperti industri manufaktur lainnya yang produksinya dapat direncanakan sesuai kebutuhan.

Untuk konsumsi garam di Indonesia, dari tahun ke tahun semakin meningkat. Pada tahun 2015 kebutuhan garam Indonesia mencapai 2,6 juta ton, meningkat 50.000 ton pada tahun sebelumnya. Yang disayangkan, garam lokal hanya terserap sekitar $80 \%$ dan selebihnya masih impor. Hal tersebut juga sangat merugikan petani garam, karena sebagian pabrik masih memilih garam impor yang terbilang murah dan kualitas lebih tinggi [3]. Dengan adanya fakta tersebut, harga garam di Indonesia sering naik-turun tidak menentu. Karena tidak hanya faktor cuaca saja yang mempengaruhi harga garam, akan tetapi faktor lain seperti kebijakan pemerintah tentang impor dan penetapan harga juga dapat mempengaruhi naik-turunnya harga garam.

Dalam upaya membantu para petani dan pengusaha yang bergerak pada bidang pengolahan garam, pada penelitian ini akan dilakukan peramalan harga garam di perusahaan PT. 
Garam Mas, dimana hasil dari peramalan tersebut setidaknya dapat membantu mereka dalam memprediksi harga di masa yang akan datang dan dapat memberikan dasar ilmiah untuk merumuskan strategi bisnisnya dengan tepat. Metode yang digunakan untuk menyelesaikan masalah tersebut adalah Artificial Neural Network, karena pada pelelitiannya sebelumnya terkait dengan peramalan harga, ditemukan bahwa metode tersebut menghasilkan tingkat akurasi yang lebih baik jika dibandingkan dengan metode yang lain dan salah satu kelebihan metode ini adalah dapat bersifat adaptif terhadap perubahan parameter, sehingga pada proses training, metode tersebut mampu belajar secara adaptif. Kemudian metode tersebut divisualisasikan agar dapat digunakan oleh PT. Garam Mas untuk melakukan peramalan di masa yang akan datang.

\section{DASAR TEORI}

\section{A. Forecasting}

Peramalan bisa menjadi hal yang penting dalam pengambilan keputusan, ada beberapa faktor yang bisa menyebabkan efektif atau tidaknya suatu keputusan, yaitu faktor-faktor yang tidak kita lihat ketika keputusan itu diambil [4]. Peramalan juga bisa digunakan dalam aktivitas bisnis dimana dapat memperkirakan jumlah penjualan dan penggunaan produk di periode yang akan datang, sehingga produk dapat dibuat dalam kuantitas yang tepat sesuai dengan hasil peramalan. Peramalan merupakan perkiraan dari permintaan yang akan datang berdasarkan pada beberapa variabel peramal yang diberdasarkan pada data histori. Peramalan bisa menggunakan teknik-teknik peramalan yang bersifat baik formal maupun informal [5].

Dalam peramalan, untuk mendapatkan hasil yang akurat dan bermanfaat, terdapat dua hal yang harus diperhatikan [6]:

1. Data yang dikumpulkan haruslah berupa informasi yang revelan sehingga dapat menghasilkan peramalan yang akurat.

2. Penggunaan metode peramalan yang tepat.

\section{B. Metode Artificial Neural Network}

Metode Artificial Neural Network (ANN) disebut juga Simulated Neural Network (SNN) dan sering disebut juga sebagai Jaringan Syaraf Tiruan (JST). Hal tersebut dikarenakan oleh metode ini merupakan tiruan susunan syaraf (neuron) manusia. ANN adalah sebuah alat pemodelan data statistik dan non statistik. ANN dapat melakukan pemodelan hubungan yang rumit (kompleks) antara input dan output dengan tujuan untuk menemukan pola pada data.

Jaringan syaraf pada manusia adalah inspirasi dari pembuatan metode ANN ini. Berikut ini dijelaskan perbedaan antara jaringan syaraf manusia dengan Artificial Neural Network (ANN).

Pada jaringan manusia dendrit berfungsi untuk menerima dan menghantarkan suatu rangsangan ke badan sel. Badan sel bertugas untuk menerima rangsangan dari dendrit dan meneruskan ke akson. Kemudian akson memiliki fungsi untuk meneruskan impuls ke neuron lainnya. [7]

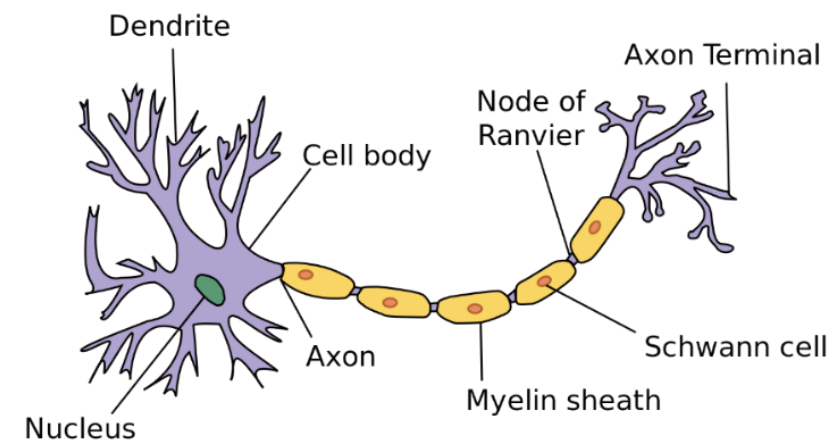

Gambar 1. Struktur Dasar Jaringan Manusia

Sedangkan pada Artificial Neural Network (ANN), strukturnya terdiri dari input layer, hidden layer dan output layer. Suatu informasi $(\alpha)$ akan diterima input layer menggunakan bobot kedatangan (w) tertentu. Setelah itu akan dilakukan penjumlahan bobot pada hidden layer. Kemudian hasil dari penjumlahan tersebut akan dibandingkan dengan nilai ambang (threshold). Jika nilai melewati ambang batas, maka akan diteruskan ke output layer, sedangkan jika nilai tidak melewati ambang batas, maka tidak akan diteruskan ke output layer.

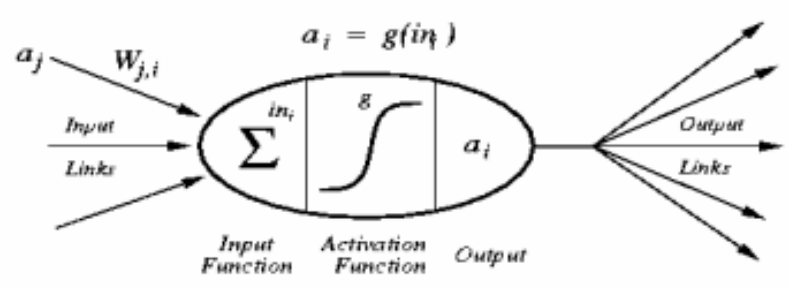

Gambar 2. Model Artificial Neural Network

\section{Matrix Laboratory (MATLAB)}

MATLAB adalah sebuah program dengan fungsi untuk menganalisis dan mengomputasi data numerik, MATLAB juga merupakan bahasa pemrograman matematika lanjut.

MATLAB merupakan bahasa pemrograman yang dikembangkan oleh The Mathwork Inc. Fungsi dan karakteristik dari bahasa pemrograman MATLAB berbeda dengan bahasa lainnya yang sudah ada seperti Delphi, Basic, maupun $\mathrm{C}++$.

MATLAB merupakan bahasa pemrograman tingkat tinggi berbasis matriks yang digunakan untuk teknik komputasi numerik untuk menyelesaikan masalah terkait operasi matematika. Berikut adalah beberapa permasalahan yang dapat diselesaikan oleh MATLAB :

- Matematika dan komputasi,

- Pengembangan dan algoritma,

- Pemrograman modeling, simulasi dan pembuatan prototipe,

- Analisis data, eksplorasi dan visualisasi,

- Analisis numerik dan statistik,

- Pengembangan aplikasi teknik.

MATLAB bersifat extensible, yaitu pengguna dapat menambahkan fungsi baru pada library MATLAB. MATLAB merupakan sistem interaktif yang elemen dasarnya tidak memerlukan dimensioning. Sehingga dapat memungkinkan penggunanya untuk menyelasaikan masalah terkait komputasi teknis, terutama matriks dan formulasi vektor. 


\section{Evaluasi Peramalan}

Untuk mendapatkan peramalan yang akurat, perlu dilakukan evaluasi terhadap hasil peramalan. Salah satu metode evaluasi yang digunakan adalah dengan melihat nilai Mean Absolute Percentage Error (MAPE). Nilai MAPE didapatkan dengan cara membagi hasil kesalahan absolut dengan nilai observasi pada setiap periode. Hasil peramalan dikatakan semakin akurat jika nilai MAPE semakin kecil. Perhitungan MAPE dirumuskan sebagai berikut :

$M A P E=\frac{\sum_{t=1}^{n}\left|\frac{x t-f t}{x t}\right|}{n} \times 100 \%$

Keterangan :

MAPE $=$ Mean Absolute Percentage Error

$\mathrm{n}=$ Jumlah Sampel

$\mathrm{xt}=$ Nilai Aktual Indeks pada period ke-t

$\mathrm{ft}=$ Nilai Prediksi Indeks pada period ke-t

Hasil perbandingan tingkat akurasi hasil pejalan berdasarkan nilai MAPE ditunukkan pada Tabel 1 [6].

Tabel 1.

Tabel Perbandingan Tingkat Akurasi MAPE

\begin{tabular}{lll}
\multicolumn{1}{c}{ MAPE } & & Tabel Perbandingan Tingkat Akurasi MAPE \\
\hline$<10 \%$ & Sangat Baik & \\
$10-20 \%$ & Baik \\
$20-50 \%$ & Layak/ Cukup & \\
$>50 \%$ & Buruk & \\
\hline \hline
\end{tabular}

\section{METODOLOGI}

\section{A. Identifikasi Permasalahan}

Tahap ini merupakan tahap awal pengerjaan penelitian ini, hal yang dilakukan adalah merumuskan masalah yang ada pada objek yang diteliti pada penelitian ini yaitu produk garam pada PT. Garam Mas, menentukan tujuan pada penelitian ini dan menentukan batasan masalah pada penelitian ini.

\section{B. Studi Literatur}

Pada tahap studi literatur merupakan tahap awal dilakukan studi pustaka tentang segala informasi yang relevan terhadap permasalahan yang ada pada penelitian studi ini.

Tahapan ini dimulai dengan pengenalan terhadap permasalahan yang diteliti dalam kasus ini permasalahan terkait penjualan garam di Indonesia, kemudian dilakukan pencarian studi pustaka yang relevan terhadap permasalahan yang diteliti yaitu tentang permasalahan yang dihadapi pada industri garam, forecasting, artificial neural networks dan matrix laboratory (MATLAB) melalui buku, jurnal, laporan penelitian, situs-situs di internet, maupun laporan penelitian lainnya. Studi literatur tersebut kemudian digunakan sebagai landasan teori pada studi ini.

\section{Pengumpulan, Penyiapan dan Pengelolaan Data}

Pada tahap ini dilakuakan pengumpulan data yang diambil dari hasil wawancara terhadap pemilik perusahaan PT. Garam Mas. Hasil dari wawancara tersebut adalah data harga penjualan produk garam kualitas II periode Januari 2010 Oktober 2016 dalam bentuk mingguan dengan jumlah data sebanyak 328 buah.

Setelah mendapatkan data, kemudian dilakukan penyiapan dan pengelolaan data. Data tersebut di plot pada grafik dan dianalisa pergerakannya. Hasil dari analisa tersebut digunkan sebagai dasar pemilihan metode peramalan.

\section{Pemodelan Artificial Neural Network}

Pada tahap ini dilakukan pemodelan Artificial Neural Network dengan penjelasan sebagai berikut :

- Menentukan variabel input layer, hidden layer dan output layer. Pada penelitian ini data harga penjualan mingguan merupakan input layer, sedangkan output layer adalah prediksi harga penjualan mingguan dalam kurun waktu satu tahun.

- Menentukan fungsi transfer yang digunakan untuk memformulasikan output pada setiap layer dan neuron. Pada software MATLAB terdapat tiga fungsi transfer yaitu Logsigmoid (logsig), Tansigmoid (tansig) dan Purelin. Untuk fungsi aktivasi pada layer output menggunakan fungsi transfer Purlin dan untuk fungsi transfer pada hidden layer menggunakan kombinasi dari ketiga fungsi transfer tersebut.

- Menentukan algoritma training dan learning function. Pada software MATLAB mempunyai beberapa algoritma training dan learning function dan dilakukan kombinasi untuk menghasilkan peramalan yang optimal.

- Menentukan learning rate yang digunakan untuk memperoleh eror yang minimal. Nilai leraning rate yang digunakan adalah $0.1-0.9$

- Menentukan epoch. Epoch digunakan membatasi proses pembacaan data. Tujuan penentuan epoch adalah untuk membatasi error agar tetap pada kondisi yang minimum

- Melakukan training dan testing pada data. Proporsi yang digunakan adalah $70 \%$ untuk data training dan $30 \%$ untuk data testing.

- Melakukan verifikasi dan validasi model. Untuk melakukan verifikasi dan validasi model pada penelitian ini, dilakukann perhitungan Mean Absolute Percentage Error (MAPE) dan dilihat hasil persentasenya.

\section{E. Melakukan Peramalan Menggunakan Metode ANN}

Pada tahapan ini dilakukan penerapan pemodelan ANN yang sudah dibuat. Proses penerapan ini menggunakan software MATLAB sebagai pendukung.

\section{F. Analisis Hasil Peramalan}

Pada tahapan ini dilakukan analisis pada hasil dari peramalan menggunakan pemodelan ANN dengan cara membandingkan data aktual dengan data peramalan. Kemudian melakukan perhitungan tingkat akurasi yang dihasilkan dari peramalan dengan melakukan pengukuran Mean Absolute Percentage Error (MAPE).

\section{G. Pembuatan Visualisasi}

Pada tahapan ini dilakukan pembuatan visualisasi hasil peramalan agar dapat dengan mudah dibaca oleh pengguna. Tujuan lain dari pembuatan visualisasi ini adalah agar kedepannya pemodelan ini dapat digunkan oleh perusahaan.

\section{H. Penyusunan Buku Laporan Studi}

Tahapan terakhir adalah dilakukan penyusunan laporan studi yang berisi tentang dokumentasi dan langkah-langkah pengerjaan.

\section{HASIL DAN PEMBAHASAN}

\section{A. Hasil Pengumpulan Data}

Pada tahapan ini dilakukan pengumulan data yang dibutuhkan pada penelitian studi ini. Pengumpulan data 
dilakukan dengan melakukan wawancara terhadap pemilik perusahaan PT. Garam Mas. Hasil dari wawancara adalah data harga penjualan produk garam kualitas II periode Januari 2010 - Oktober 2016 dalam bentuk mingguan dengan jumlah data sebanyak 328 buah. Hasil plot data ditunjukkan pada Gambar 3.

Harga Garam Periode 2010-2016

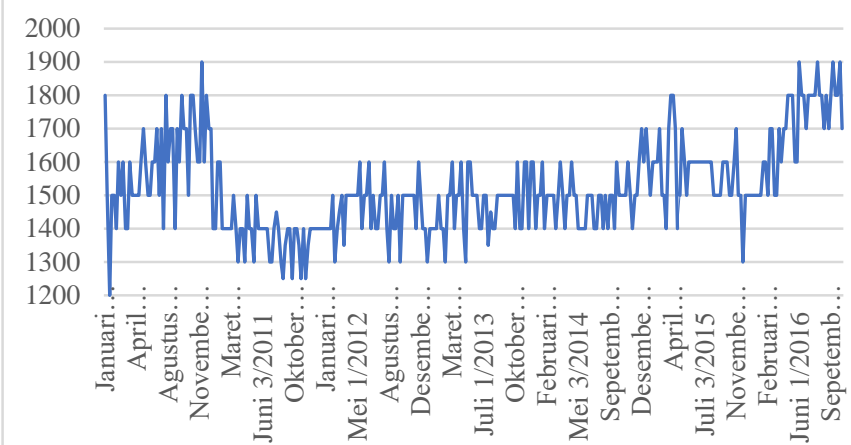

Gambar 3. Hasil Plot Data

\section{B. Pembagian Data Training dan Data Testing}

Data yang digunakan adalah data harga penjualan garam dalam bentuk mingguan pada tahun 2010 - 2016 berjumlah 328 buah. Dalam melakukan pengolahan data, penulis membagi data menjadi dua, yaitu data pelatihan (training) dan data pengujuan (testing). Dimana data training sebesar 70\% (230 data) dam data testing sebesar 30\% (98 data). Gambar 4 dan Gambar 5 merupakan grafik dari data training dan data testing yang digunakan pada penelitian studi ini.

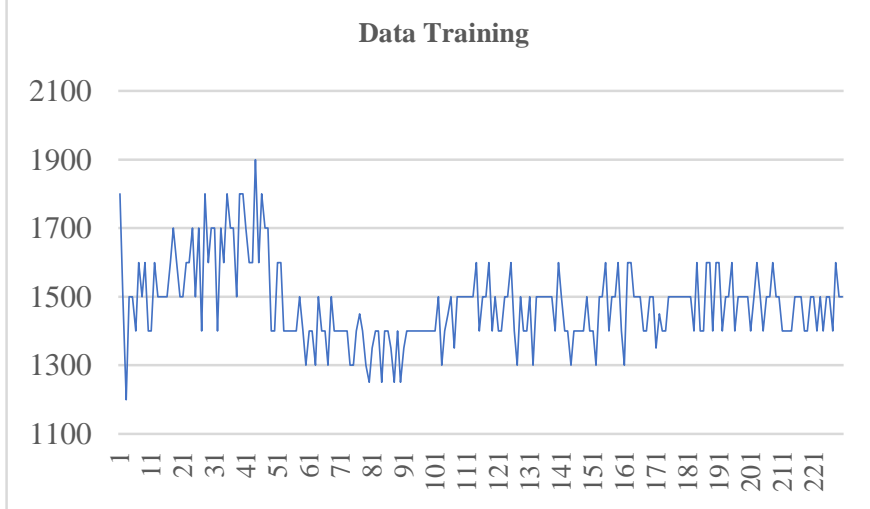

Gambar 4. Data Training

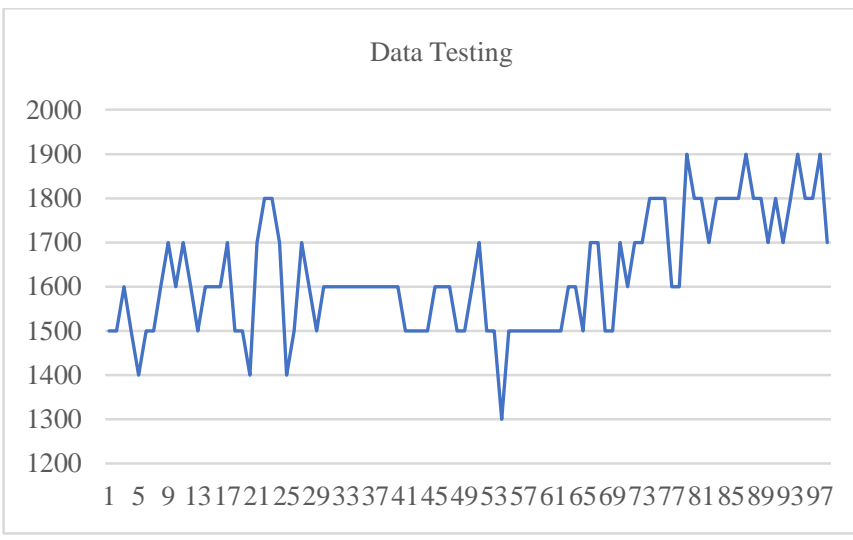

Gambar 5. Data Testing

\section{Penentuan Parameter}

Untuk mendapatkan model terbaik sesuai dengan permasalahan yang ada perlu dilakukan pengubahan terhadap parameter. Pengubahan terhadap parameter yang ada ditujukan untuk mencari MAPE yang paling rendah.

Berikut ini dijelaskan pengubahan parameter yang ada pada penelitian studi ini :

a. Fungsi Pelatihan (training function)

Pada studi ini menggunkan 14 training function yaitu BFGS quasi-Newton backpropagation, Bayesian regularization backpropagation, Conjugate gradient backpropagation with PowellBeale restarts, Conjugate gradient backpropagation with Fletcher-Reeves updates, Conjugate gradient backpropagation with Polak-Ribiére updates, Gradient descent backpropagation, Gradient descent with momentum backpropagation, Gradient descent with adaptive learning rate backpropagation, Levenberg-Marquardt backpropagation, One-step secant backpropagation, Resilient backpropagation, Scaled conjugate gradient backpropagation, Gradient descent with momentum and adaptive learning rate backpropagation, Random order incremental training with learning functions. Training function tersebut adalah semua jenis training function yang ada pada aplikasi MATLAB. Penggunaan variasi semua jenis traininig function diharapkan agar mendapatkan model yang paling optimal.

b. Fungsi Pembelajaran (adaption learning function) Pada penelitian studi ini dilakukan trial and error pada pencarian parameter adaption learning function. Jenis adaption learning function yang digunakan pada penelitian studi ini sebanyak 2 jenis yaitu learningd dan learningdm. Hasil dari pencarian parameter ini adalah gradient yang paling optimal terhadap berat (weight) dan bias pada model.

c. Fungsi Transfer (transfer function)

Pada penelitian ini dilakukan trial and eror untuk mencari parameter fungsi transfer (transfer function). Jenis transfer function yang digunakan sebanyak 3 jenis yaitu Logsigmoid (logsig), Transigmoid (tansig) dan Purelinear (purelin) yang digunakan pada layer pertama, sedangkan pada layer kedua yaitu sebagai output layer menggunakan fungsi Purelinear (purelin). Transfer function berrguna untuk mendapatkan nilai dari hasil pengolahan berat (weight) dengan node.

d. Jumlah Epoch

Jumlah epoch mempengaruhi dalam performa model dikarenakan epoch dapat menentukan pemberhentian proses training. Pada penelitian studi ini, jumlah epoch yang digunakan adalah 1000 .

Untuk mengetahui lebih jelas tentang penentuan hidden layer dan parameter pada penelitian studi ini ditunjukkan pada Tabel 2.

Tabel 2.

Penentuan Hidden Layer

\begin{tabular}{lcc}
\hline \hline \multicolumn{1}{c}{ Jenis Parameter } & Jumlah & Keterangan \\
\hline $\begin{array}{l}\text { Jumlah Node pada } \\
\text { Hidden Layer }\end{array}$ & 2-20 Node (19) & Trial and Erorr \\
$\begin{array}{l}\text { Fungsi Pelatihan } \\
\text { (training function) }\end{array}$ & 14 & Trial and Erorr \\
$\begin{array}{l}\text { Fungsi Pembelajaran } \\
\text { (adaption learning }\end{array}$ & 2 & Trial and Erorr \\
function) & & \\
$\begin{array}{l}\text { Fungsi Transfer } \\
\text { (transfer function) }\end{array}$ & 3 & Trial and Erorr \\
\hline \hline
\end{tabular}




\begin{tabular}{lcc}
\hline \hline Jumlah Epoch & 1000 & Trial and Erorr \\
\hline \hline
\end{tabular}

\section{Hasil Percobaan}

Dari hasil percobaan yang telah dilakukan pada setiap model dengan mengubah parameter, akan dianalisis lebih lanjut untuk mendapatkan model yang paling optimum. Hasil parameter terbaik dari masing-masing model ditampilkan pada Tabel 3 dan pada kolom terakhir ditampilkan perbandingan nilai MSE dari masing-masing model yang diuji coba.

Tabel 3.

Hasil Percobaan Model

\begin{tabular}{cccccc}
\hline \hline Input & $\begin{array}{c}\text { Node } \\
\text { Hidden } \\
\text { Layer }\end{array}$ & $\begin{array}{c}\text { Fungsi } \\
\text { Pelatihan }\end{array}$ & $\begin{array}{c}\text { Fungsi } \\
\text { Pembelajara } \\
\mathrm{n}\end{array}$ & $\begin{array}{c}\text { Fungsi } \\
\text { Transfer }\end{array}$ & MSE \\
\hline Node 1 & 11 & traingda & learngdm & purelin & 9610.66 \\
Node 2 & 14 & traincgb & learngd & purelin & 9629.856 \\
Node 3 & 7 & traingdx & learngdm & purelin & 9230.267 \\
Node 4 & 13 & traingdx & learngd & purelin & 9106.408 \\
Node 5 & 15 & trainoss & learngdm & purelin & 8593.915 \\
Node 6 & 8 & traingda & learngd & purelin & 8387.902 \\
Node 7 & 13 & traingda & learngd & logsig & 8576.66 \\
Node 8 & 16 & traingda & learngdm & purelin & 8713.141 \\
\hline \hline
\end{tabular}

Kemudian agar mudah dalam mendapatkan nilai yang paling minimum, pada Gambar 6 ditampilkan grafik perbandingan nilai MSE pada setiap model.

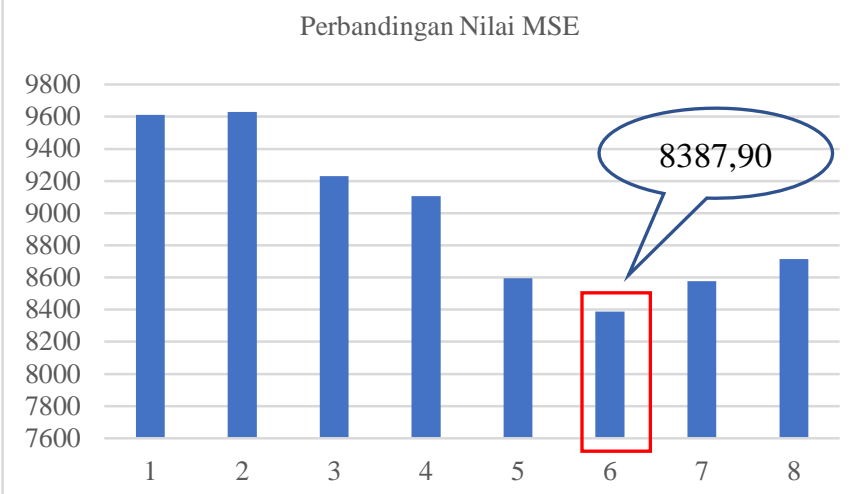

Gambar 6. Grafik Perbandingan Nilai MSE

Dari Gambr 6 dapat disimpulkan bahwa nilai MSE paling minimum adalah model node input 6 dengan nilai MSE 8387,902 .

Untuk memilih model yang paling optimum dipilih berdasarkan nilai MSE yang paling minimum. Dan hasilnya model node input 6 dengan parameter 8 node pada hidden layer dengan fungsi pelatihan traingda, fungsi pembelajaran learngd, fungsi transfer purelin dan epoch 1000 adalah model yang paling optimum. Untuk mengetahui tingkat error yang dihasilkan, dilakukan dengan mencari nilai MAPE dan dihasilkan nilai sebesar $4.394 \%$.

\section{E. Visualisasi Data}

Setelah mendapatakan model yang optimal, kemudian dilakukan pembuatan Graphic User Interface (GUI) yang ditujukan agar pengguna dapa dengan mudah menggunakan model tersebut untuk melakukan peramalan dengan data yang diinginkan. Gambar 9 menampilkan GUI tersebut.

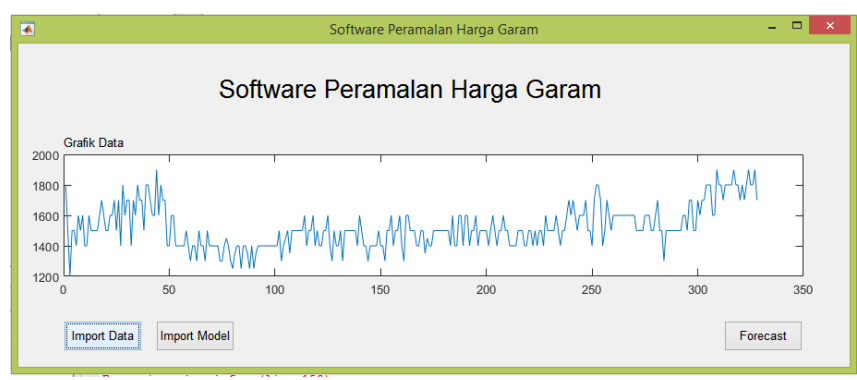

Gambar 7. GUI Peramalan

\section{KESIMPULAN DAN SARAN}

\section{A. Kesimpulan}

Berdasarkan hasil uji coba yang telah dilakukan dalam penelitian studi ini, maka kesimpulan yang dapat diambil adalah :

1. Metode Artificial Neural Network (ANN) dapat digunakan untuk melakukan peramalan harga garam, sehingga dapat membantu dalam melakukan pengambilan keputusan terkait dengan penjualan garam.

2. Nilai MAPE yang dihasilkan pada saat melakukan testing model, didapatkan sebesar $4.394 \%$. hal ini menunjukkan bahwa dalam penerapan metode Artificial Neural Network pada peramalan harga garam hasilnya sangat baik.

\section{B. Saran}

Berdasarkan kesimpulan dari penelitian studi ini, diberikan rekomendasi berupa saran. Saran yang diberikan oleh penulis bagi penelitian selanjutnya adalah :

1. Uji coba yang dilakukan pada penelitian studi ini hanya terbatas pada data harga garam pada PT. Garam Mas, Rembang, Jawa Tengah, untuk peelitian selanjutnya dapat mengambil data pada perusahaan dengan skala produksi dan penjualan yang lebih besar, agar mendapatkan data yang lebih bervariasi dan memiliki periode yang lebih panjang.

2. Variabel yang digunakan pada penelitian studi ini menggunakan 1 variabel, yaitu harga garam. Pada penelitian selanjutnya disarankan dapat menambah variabel lainnya seperti cuaca, jumlah produksi, dan lain-lain. Sehingga dihasilkan model yang lebih optimal.

\section{DAFTAR PUSTAKA}

H. Gunawan, "INDUSTRI / AGRIBISNIS," 2017. [Online]. Available: http://industri.kontan.co.id/news/kemperin-garamindustri-dan-konsumsi-itu-berbeda.

Hasbitc, Cara Pembuatan Garam. 2013.

K. P. R. Indonsia, "Kebutuhan Garam Naik Tajam," 2015.

[4] S. Pangestu, Forecasting: Konsep dan aplikasi Edisi Kedua. Yogyakarta: BPFE, 1986.

[5] V. Gaspersz, Production Planning and Inventory Control. Jakarta: Gramedia Pustaka Utama, 1998.

[6] S. W. Makridakis, Metode dan Aplikasi Peramalan Edisi Kedua Jilid I. Erlangga, 1999

[7] P. E. N. Surabaya, "Bab 8: Jaringn Syaraf Tiruan," neural network, 2017. [Online]. Available: http://entin.lecturer.pens.ac.id/Kecerdasan Buatan/Buku/ 